\title{
Correction to: Toxicity prediction and assessment of an environmentally realistic pesticide mixture to Daphnia magna and Raphidocelis subcapitata
}

\author{
E. Silva ${ }^{1} \cdot$ C. Martins ${ }^{1} \cdot$ A. S. Pereira ${ }^{1} \cdot$ S. Loureiro ${ }^{2} \cdot$ M. J. Cerejeira ${ }^{1}$ \\ Published online: 16 October 2018 \\ (c) Springer Science+Business Media, LLC, part of Springer Nature 2018
}

Correction to: Ecotoxicology (2018) 27:956-967; https:// doi.org/10.1007/s10646-018-1938-0.

The acknowledgement section in the original article was published incorrectly.

The appropriate version is given below.
Acknowledgements This work was supported by LEAF (UID/AGR/ 04129/2013) and CESAM (UID/AMB/50017/2013) from FCT/MEC through national funds, and the cofunding by FEDER (POCI-01-0145FEDER-007638), within the PT2020 Partnership Agreement and Compete 2020.
The original article can be found online at https://doi.org/10.1007/ s10646-018-1938-0.

\section{E. Silva}

emiliasilva@isa.ulisboa.pt

1 LEAF, Linking Landscape, Environment, Agriculture and Food, Instituto Superior de Agronomia, Universidade de Lisboa, Tapada da Ajuda, 1349-017 Lisboa, Portugal

2 Department of Biology and CESAM, University of Aveiro, 3810193 Aveiro, Portugal 